\title{
Implementation of formal prescription guidelines reduces the economic cost of unused opioids after orthopedic surgery
}

\author{
Jacob J Schaefer, BS; Cyrus M Nouraee, BS; Nathan T Blake, PharmD; Rebecca Stone McGaver, MS, ATC; \\ Rachel M Uzlik, BS, CPHQ; Gary E Wyard, MD; and M Russell Giveans, PhD
}

\section{What is already known about this subject}

- There is a significant amount of monetary waste due to the overprescription and under-consumption of prescription medications in the US health care system.

- It has been documented that there are often more opioid pills that are prescribed than consumed, especially in orthopedic surgery, yet how this translates into monetary waste is unclear.

\section{What this study adds \\ - This study demonstrates the specific cost of waste in dollars that exists as a result of the over-prescription and under-consumption of opioid pills following orthopedic surgery. \\ - This research shows that the cost of waste of over-prescribed opioid pills following orthopedic surgery may be significantly reduced following implementation of formal internal prescription guidelines.}

\section{ABSTRACT}

BACKGROUND: Prior literature has reported on the concerning emergence of opioid overprescribing, yet there remains a lack of knowledge in understanding the cost of waste of this over-prescription and underconsumption of opioids. As such, further investigating the cost of waste of opioids following orthopedic surgery is of interest to patients, providers, and payors. In one of the largest private orthopedic practices in the United States, opioid prescribing and consumption patterns were tracked prior to, and after the implementation of, formal prescription guidelines.

OBJECTIVES: To (1) establish the cost of waste of unused opioids before the implementation of formal prescription guidelines and (2) examine how the cost of unused opioids may be reduced after implementation of formal internal prescription guidelines.

METHODS: Two separate phases (Phase I and Phase II) were implemented at different time intervals throughout a two-year period. Implementation of prescription guidelines occurred between Phases I and II, and data from Phase I (pre-implementation) was compared to that from Phase II (postimplementation). Data collection included type, dosage, quantity of opioids prescribed and consumed after elective outpatient procedures in ambulatory surgery centers, in addition to patient interviews/surveys within two weeks after surgery to measure consumption. From these data, the cost of waste was calculated by taking the total cost of prescribed opioids (sum of each prescription $\times$ Average Wholesale Price (AWP) minus 60\%) per 1,000 patients, and subtracting the total

\author{
Author affiliations \\ Jacob J Shaefer, BS; Cyrus M Nouraee, BS; \\ Nathan T Blake, PharmD; Rebecca Stone \\ McGaver, MS, ATC; Rachel M Uzlik, BS, \\ $\mathrm{CPHQ}$, Revo Health, Golden Valley, MN. Gary \\ E Wyard, MD; M Russell Giveans, PhD, Twin \\ Cities Orthopedics, Golden Valley, MN.
}

AUTHOR CORRESPONDENCE: Jacob J Schaefer, schae835@umn.edu

J Manag Care Spec Pharm. 2021;27(8):1027-34

Copyright $@ 2021$, Academy of Managed Care Pharmacy. All rights reserved.

cost of consumed opioids per 1,000 patients, calculated in a similar manner. Further analysis was performed to describe differences in the cost of waste of individual opioids between each of the phases.

RESULTS: In Phase I, prior to implementation of formal internal prescription guidelines, there was a sizable cost of waste of unused opioids (per 1,000 patients, AWP minus 60\%) of $\$ 11,299.51$. The cost of waste in Phase II, after implementation of formal internal prescription guidelines, was $\$ 6,117.12$, which was a significant decrease of $45.9 \%(\$ 5,182.39)$ from Phase I $(P<0.001)$. Furthermore, both the average number of morphine equivalent units prescribed and consumed per patient decreased from Phase I to Phase II (294.6 vs $187.8, P<0.001$; and 144.9 vs $96.0, P<0.001$, respectively). Finally, in describing individual medications, there was a significant decrease in cost of waste (per 1,000 patients, AWP 
minus 60\%) between Phases I and II for- Hydrocodone with APAP $5 / 525 \mathrm{mg}(P<0.001)$, Oxycodone CR $10 \mathrm{mg}(P<0.001)$, Morphine CR 15 $\mathrm{mg}(P=0.001)$, and Tramadol

$50 \mathrm{mg}(P=0.014)$.

CONCLUSIONS: The results of this study suggest that there is a significant cost of waste associated with differences in prescribed versus consumed opioids following elective orthopedic surgery. This cost of waste was significantly reduced following the introduction and implementation of formal prescription guidelines.

The economic impact of over-prescribed and under-consumed prescription medications (PMs) is becoming an exceedingly challenging phenomenon. In 2012 alone, the total cost of unfilled, abandoned, or unused PMs in the US health care system was conservatively estimated at $\$ 14$ billion, ${ }^{1}$ while another study in 2015 estimated that the total waste of unused PMs in the United States may exceed \$117 billion. $^{2}$

Coupled with a subsequent assortment of unintended secondary consequences, opioids are perhaps some of the most problematic, overprescribed PMs. The 2019 National Survey on Drug Use and Health reported that 10.3 million people misused an opioid in 2018, with more than half of people obtaining the medications from a friend or relative. ${ }^{3}$ In 2017, there were approximately 47,600 deaths involving an opioid overdose. ${ }^{4}$ Yet, despite several initiatives to establish better prescribing guidelines, especially after surgery, ${ }^{5,6}$ there is evidence that many opioids are still being prescribed in excess. ${ }^{7}$ An analysis, conducted by the Kaiser Family Foundation, found that while the use of prescription opioids among people with employer-based health coverage has declined, the cost of treating addiction and overdoses continues to rise. ${ }^{8}$

In particular, since orthopedic surgeons represent the third highest prescribers of opioids in the United States, ${ }^{9}$ studies have assessed the relative discrepancies between physician prescription and patient consumption of opioids following orthopedic surgery. In one study analyzing 1,199 orthopedic procedures, there were $>43,000$ prescribed opioids that were unused by patients during the analysis year, with patients being prescribed an excess of pills approximately $60 \%$ of the time. ${ }^{10}$ In addition, another study of opioid prescription habits following upper-extremity surgical procedures found that patients had an average opioid consumption rate of just $34 \%{ }^{11}$
Although there is clear data suggesting both that a large number of opioids are unused by patients after orthopedic surgery, as well as the harmful secondary consequences of misuse, there is a lack of information regarding the consequent monetary cost of these low consumption rates. As such, a cost analysis of opioid waste post-orthopedic surgery provides value not only to patients by providing cost-savings by having prescriptions with the optimal number of opioid pills, but also to providers and payors as care is continually evaluated to be delivered in the most costeffective manner.

To analyze and effectively mitigate the monetary waste of unused opioids following orthopedic surgery, Twin Cities Orthopedics (TCO), one of the largest (115 physicians) privately owned orthopedic practices in the United States,${ }^{12}$ developed a two-phase study to identify and establish prescribing guidelines. The first aim, in the absence of any formal prescription guidelines, was to establish the cost in dollars of unused opioids following orthopedic surgery. The second aim was to report how the introduction of prescription guidelines encouraging reduction in overprescribing of opioids may lessen the cost of opioid waste following orthopedic surgery. Therefore, it was hypothesized that there exists a significant proportion of unused opioids that contribute to monetary waste and that by implementing internal prescription guidelines, this waste may be significantly reduced.

\section{Methods}

The study was approved through an Institutional Review Board. Data was collected in two separate phases between summer 2017 through summer 2019. Data collection included retrospective chart review for opioid prescription quantities as well as patient interviews/surveys for patient consumption of opioids. Patient data collection was focused solely on ambulatory surgery center (ASC) patients who underwent an elective outpatient orthopedic surgical procedure performed by a TCO surgeon within one of the five Revo Health managed ASCs. The data collected in the two phases was used to compare the average cost and waste of unused opioid prescriptions following surgery. Patients were excluded on the basis of: (1) not having patient-reported consumption data and (2) having a procedure that involved Tenex, epidural steroid injections, and outpatient total joint replacements (knee, hip, shoulder, ankle and disc). To better generalize results to the population level, cost of waste was extrapolated to per 1,000 patients. 


\section{TABLE 1 Formal Prescription Guidelines by Drug and Maximum Morphine Equivalence Units (MEUs) for the Ten Most Common Orthopedic Procedures}

\begin{tabular}{|c|c|c|c|c|c|c|c|c|c|}
\hline & $\begin{array}{c}\text { Hydro- } \\
\text { codone } \\
\text { with APAP } \\
5 / 325 \mathrm{mg}\end{array}$ & $\begin{array}{c}\text { Hydro- } \\
\text { codone } \\
\text { with APAP } \\
10 / 325 \mathrm{mg}\end{array}$ & 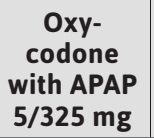 & $\begin{array}{l}\text { Hydro- } \\
\text { morphone } \\
2 \mathrm{mg}\end{array}$ & $\begin{array}{l}\text { Morphine } \\
\text { CR } 15 \mathrm{mg}\end{array}$ & $\begin{array}{c}\text { Oxy- } \\
\text { codone } \\
10 \mathrm{mg}\end{array}$ & $\begin{array}{l}\text { Oxy- } \\
\text { codone } \\
5 \mathrm{mg}\end{array}$ & $\begin{array}{l}\text { APAP with } \\
\text { codeine } \\
30 / 300 \mathrm{mg}\end{array}$ & $\begin{array}{l}\text { Tramadol } \\
50 \mathbf{~ m g}\end{array}$ \\
\hline $\begin{array}{l}\text { ORIF distal radius and ulna } \\
\text { (max } 150 \mathrm{MEU})\end{array}$ & $10-30$ & $5-15$ & $6-20$ & $6-20$ & $2-6$ & $3-9$ & $6-18$ & $11-33$ & $10-30$ \\
\hline Carpal tunnel release (0 MEUs) & 0 & 0 & 0 & 0 & 0 & 0 & 0 & 0 & 0 \\
\hline Laminectomy (Max 150 MEU) & $10-30$ & $5-15$ & $6-20$ & $6-20$ & $2-6$ & $3-9$ & $6-18$ & $11-33$ & $10-30$ \\
\hline $\begin{array}{l}\text { Ankle scope with debridement } \\
\text { (max } 114 \text { MEUs) }\end{array}$ & 22 & 11 & 15 & 14 & 5 & 7 & 15 & 25 & 22 \\
\hline $\begin{array}{l}\text { Hip scope debridement } \\
\text { (max } 150 \text { MEUs) }\end{array}$ & $10-30$ & $5-15$ & $6-20$ & $6-20$ & $2-6$ & $3-9$ & $6-18$ & $11-33$ & $22-33$ \\
\hline ACL repair (max 168 MEUs) & $22-33$ & $11-16$ & $15-22$ & $14-21$ & $5-7$ & $7-11$ & $15-22$ & $25-37$ & $22-33$ \\
\hline $\begin{array}{l}\text { Knee scope with medial or } \\
\text { lateral meniscus repair } \\
\text { (max } 100 \text { MEUs) }\end{array}$ & 20 & 10 & 13 & 12 & 4 & 7 & 13 & 22 & 20 \\
\hline $\begin{array}{l}\text { Knee scope with meniscectomy } \\
\text { (max } 100 \text { MEUs) }\end{array}$ & 20 & 10 & 13 & 12 & 4 & 7 & 13 & 22 & 20 \\
\hline $\begin{array}{l}\text { Shoulder scope with } \\
\text { decompression (max } 114 \text { MEUs) }\end{array}$ & 22 & 11 & 15 & 14 & 5 & 7 & 15 & 25 & 22 \\
\hline $\begin{array}{l}\text { Shoulder scope with RCR } \\
\text { (max } 225 \text { MEUs) }\end{array}$ & 45 & $15-25$ & $20-33$ & $18-31$ & $6-11$ & $10-25$ & $20-33$ & $22-44$ & $30-50$ \\
\hline
\end{tabular}

Guidelines were implemented in March 2018.

$A C L=$ anterior cruciate ligament; $A P A P=$ acetaminophen; $M E U s=$ morphine equivalence units; $O R I F=$ open reduction internal fixation; $R C R=$ rotator cuff repair.

\section{PHASE I}

Phase I occurred between July 2017 and December 2017, involving consecutive surgeries during two 2-week periods during this time interval at three Revo Health managed ASCs. Chart review was performed for prescription data including: the type, dosage, and quantity of opioids prescribed after surgical cases. Patient consumption data was obtained by calling patients 14 days \pm 3 days postoperatively. Patients consented verbally and were asked about the utilization of their prescribed opioids. They were specifically asked how many pills they had taken and how many refills they had received. Patients were called back up to three times if they did not answer. Formal internal prescription guidelines were established following this phase in March, 2018 (Table 1).

\section{PHASE II}

Phase II occurred between May 2018 and August 2019 and included all surgeries at one of five ASCs (including the three ASCs previously looked at in Phase I). Data collection was otherwise the same except for the method in which data was obtained. This phase initially relied on patient interviews via answered phone calls, although it developed to include all patients who responded to an automatic online postoperative medication survey following their respective orthopedic surgeries. In this phase, patients were also educated by surgery center nursing staff about proper opioid usage prior to discharge.

\section{DRUG PRICING}

Drug prices were calculated using the average wholesale price (AWP) of the generic drug from Medi-Span. ${ }^{13}$ The median cost of the generic drug was used. The estimated payor cost, or price that payors actually pay for each opioid pill, was calculated using a $60 \%$ discount from the AWP. ${ }^{14}$ The median AWP and estimated payor cost (AWP minus $60 \%$ ) per pill of the generic form of each opioid analyzed in this study is shown in Table 2. From these data, the cost of waste was calculated by taking the total cost of prescribed opioids (sum of each prescription $\times$ AWP minus $60 \%$ ) per 1,000 patients, and subtracting the total cost of consumed opioids per 1,000 patients, calculated in a similar manner. 


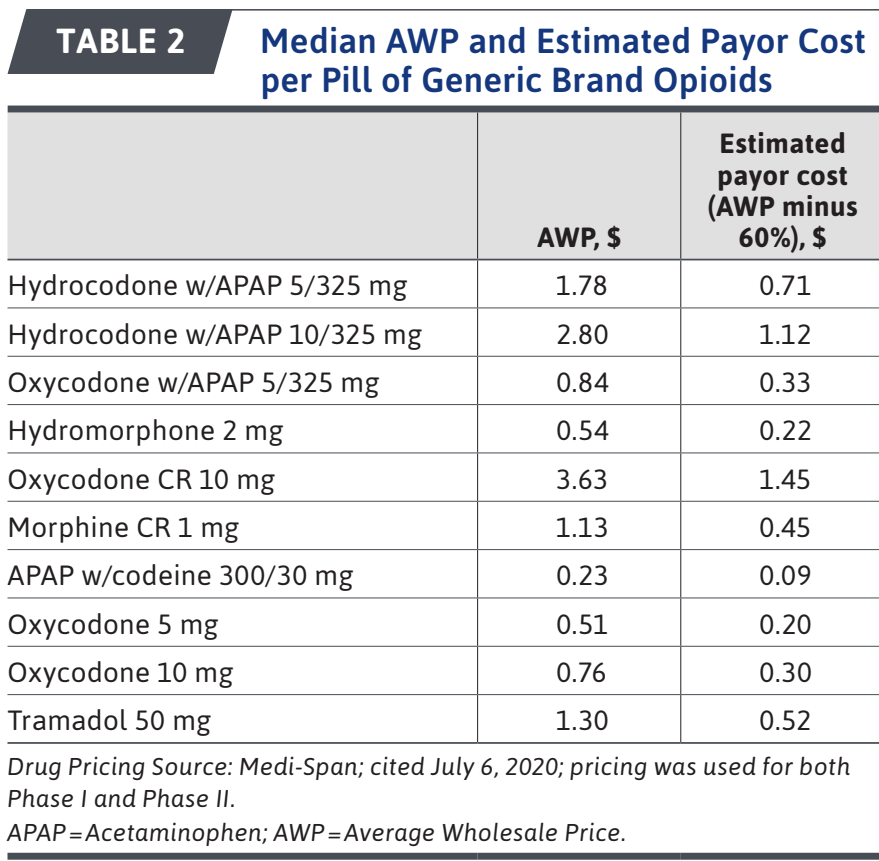

\section{STATISTICAL ANALYSIS}

Independent samples t-tests were performed to determine significant differences between the two phases. Cost data were determined to be non-normal through KolmogorovSmirnov tests for normality, and thus Mann-Whitney U tests were utilized where applicable. Chi-square analyses were also used for percentages between the two phases. Statistical analysis was performed using SPSS v24 (IBM Corp. Released 2016. IBM SPSS Statistics for Windows, Version 24.0. Armonk, NY: IBM Corp.), with the level of significance set at $\mathrm{P}<0.05$.

\section{Results}

\section{PATIENT CHARACTERISTICS}

Throughout both phases of the study, the average age of the patients was not statistically different. Phase I included 350 patients with an average age of 52.1 years old with 191 females (54.6\%), and in Phase II, there were 4,123 patients with an average age of 51.5 and 2,430 females (58.9\%; Table 3).

Average Morphine Equivalent Units (MEUs) Prescribed and Consumed in Phases I and II. In Phase I there was an average of 294.6 MEUs prescribed, whereas in Phase II there was an average of 187.8 MEUs prescribed per patient, which was significantly lower $(\mathrm{P}<0.001)$. In Phase I there was an average of 144.9 MEUs consumed, whereas in Phase II there was an average of 96.0 MEUs consumed per patient, which was significantly lower $(\mathrm{P}<0.001)$.

Overall Cost of Waste Per 1,000 Patients AWP Minus 60\%. The overall cost of waste per 1,000 patients AWP minus $60 \%$ for each phase of the study is shown in Figure 1. The overall cost of prescriptions per 1,000 patients AWP minus $60 \%$ in Phase I was $\$ 20,867.63$ and $\$ 12,024.96$ in Phase II. This led to a significant decrease in the cost of prescriptions of $42.4 \%$ (\$8,842.67; $\mathrm{P}<0.001)$. The total cost of consumption per 1,000 patients AWP minus $60 \%$ in Phase I was $\$ 9,568.13$ and $\$ 5,907.84$ in Phase II. This led to a significant overall decrease in cost of consumption per 1,000 patients AWP minus $60 \%$ of $38.3 \%(\$ 3,660.29 ; \mathrm{P}<0.001)$. The overall total cost of waste per 1,000 patients AWP minus $60 \%$ in Phase I was $\$ 11,299.51$ and $\$ 6,117.12$ in Phase II. This led to a significant overall decrease in cost of waste per 1,000 patients AWP minus $60 \%$ of $45.9 \%$ ( $\$ 5,182.39 ; \mathrm{P}<0.001)$

Individual Opioid Cost of Prescription Per 1,000 Patients, AWP Minus $60 \%$. The cost of prescription per 1,000 patients AWP minus $60 \%$, for each individual opioid during Phases I and II is shown in Table 4. There was a significant decrease between Phases I and II after implementation of formal internal prescription guidelines for Hydrocodone with APAP 5/525 mg $(\mathrm{P}<0.001)$, Oxycodone CR $10 \mathrm{mg}$ $(\mathrm{P}<0.001)$, Morphine $\mathrm{CR} 15 \mathrm{mg}(\mathrm{P}=0.009)$, and Tramadol $50 \mathrm{mg}(\mathrm{P}=0.012)$.

Individual Opioid Cost of Consumption Per 1,000 Patients, AWP Minus $60 \%$. The cost of consumption per 1,000 patients, AWP minus $60 \%$ for each individual opioid during Phases I and II is shown in Table 5. There was a significant decrease between Phases I and II after implementation of formal internal prescription guidelines for Hydrocodone with APAP 5/525 mg $(\mathrm{P}<0.001)$, Oxycodone $\mathrm{CR} 10 \mathrm{mg}$ $(\mathrm{P}<0.001)$, Morphine $\mathrm{CR} 15 \mathrm{mg}(\mathrm{P}=0.003)$, and Tramadol $50 \mathrm{mg}(\mathrm{P}=0.037)$.

Individual Opioid Cost of Waste Per 1,000 Patients, AWP Minus $60 \%$. The cost of waste per 1,000 patients, AWP minus $60 \%$ for each individual opioid during Phases I and II is shown in Table 6 . There was a significant decrease between Phases I and II after implementation of formal internal prescription guidelines for Hydrocodone with APAP 5/525 mg $(\mathrm{P}<0.001)$, Oxycodone CR $10 \mathrm{mg}(\mathrm{P}<0.001)$, Morphine $\mathrm{CR}$ $15 \mathrm{mg}(\mathrm{P}=0.001)$, and Tramadol $50 \mathrm{mg}(\mathrm{P}=0.014)$.

\section{Discussion}

The current study investigated two central aims: first, to establish the cost of waste of unused opioids following 


\begin{tabular}{l|c|c|c}
\multicolumn{1}{c|}{ TABLE 3 } & \multicolumn{2}{|c}{$\begin{array}{l}\text { Patient } \\
\text { Characteristics }\end{array}$} \\
\hline & Phase I & Phase II & P value \\
\hline Sample Size (n) & 350 & 4,123 & N/A \\
\hline Total males & 159 & 1,693 & 0.111 \\
\hline Total females & 191 & 2,430 & 0.111 \\
\hline Average age & 52.1 & 51.5 & 0.462 \\
\hline
\end{tabular}

elective orthopedic surgeries in ASCs, and second, to investigate how implementing internal formal prescription guidelines may reduce the cost of waste of unused opioid pills. The current study demonstrated that there was a significantly higher cost of waste of unused opioids in Phase I following orthopedic surgery before the implementation of any formal guidelines (Figure 1). This has important implications, especially for payors, in delivering optimal cost-effective care. According to a 2019 report by Blue Cross Blue Shield, elective orthopedic procedures for their insured members cost around $\$ 25$ billion or $47 \%$ of their total orthopedic care spending in 2017. ${ }^{15}$ Studies have shown that a large contribution to the cost of orthopedic care is associated with imaging studies, hospital admissions, implant costs, and that focusing on surgeon education, improving operating room efficiency, and implementing values analysis teams may reduce this waste. ${ }^{16,17}$ With that acknowledged, the results of this study suggest that reducing the cost of waste of unused opioid prescriptions may also be beneficial.

Specifically, following the implementation of formal internal prescription guidelines after Phase I, there were significant decreases in the cost of prescription, consumption, and in the cost of waste of unused opioids, respectively, between Phases I and II (Figure 1). Overall, from the

\section{FIGURE 1 Cost of Waste per 1,000 Patients, AWP Minus 60\%}

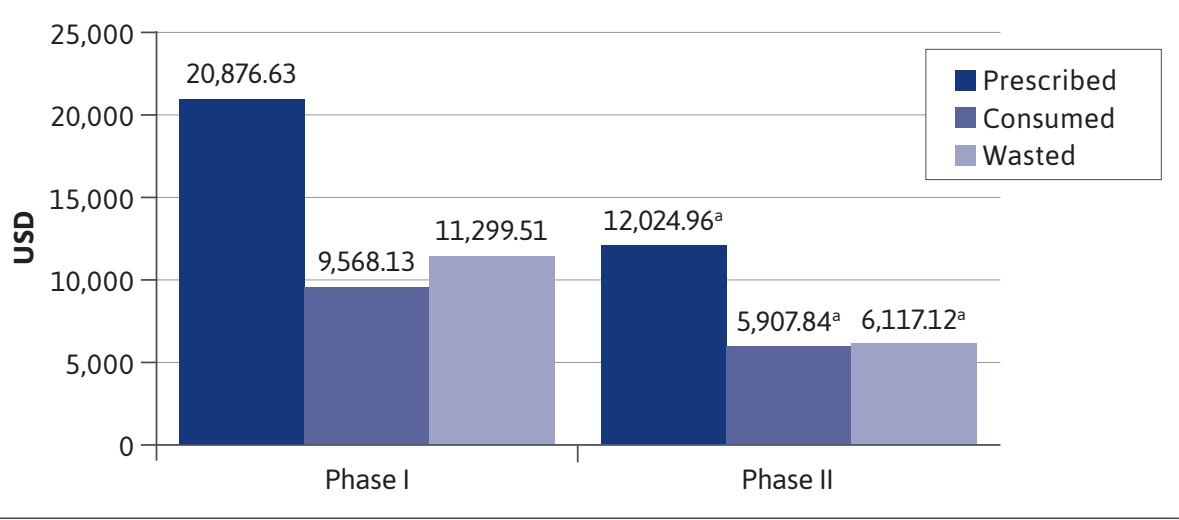

asignificant difference from Phase I.

$A W P=$ Average Wholesale Price.

inception of the study in the summer of 2017 to its conclusion in the summer of 2019, TCO surgeons were able to effectively reduce prescription costs associated with opioids by $42.4 \%$, leading to a $45.9 \%$ decrease in the cost of waste of opioids that were unused by patients. Average total MEUs prescribed per patient also significantly decreased between Phase I and II. As such, implementation of prescription guidelines successfully reduced the overall cost of prescription and waste associated with unused opioids. As other studies have suggested, implementation of prescription guidelines can effectively reduce the amount of opioid prescriptions, but this study adds consideration to the monetary savings associated with implementing guidelines. ${ }^{18,19}$ Furthermore, patients also consumed significantly less MEUs between Phase I and Phase II. This can be attributed to a renewed emphasis in Phase II on educating patients about the harmful effects of inappropriate opioid use. Focusing efforts on curtailing excess prescription medication use, while also increasing patient education, may effectively reduce the total cost of orthopedic care.
Wunsch et al. reported that approximately $80 \%$ of patients are prescribed opioids after low-risk surgical procedures such as carpal tunnel release or knee arthroscopy, and that over $80 \%$ of these opioid prescriptions involve either oxycodone or hydrocodone. ${ }^{20}$ In this current study, the two biggest pill-specific decreases in the cost of waste were Oxycodone CR $10 \mathrm{mg}$ and Hydrocodone with APAP $5 / 325 \mathrm{mg}$. These two frequently prescribed opioids were also the most expensive (Oxycodone CR $10 \mathrm{mg}$ ) and third-most expensive (Hydrocodone with APAP 5/325 mg) medications in this current study. As a result, it is especially encouraging that TCO was able to significantly reduce the cost of prescription of Oxycodone CR $10 \mathrm{mg}$ by $93.0 \%$ and Hydrocodone with APAP $5 / 325 \mathrm{mg}$ by $46.0 \%$ from Phase I to II. This translated to a reduction in the cost of waste of Oxycodone CR $10 \mathrm{mg}$ by $94.2 \%$ and Hydrocodone with APAP $5 / 325 \mathrm{mg}$ by $49.8 \%$. This reduction in the cost of waste may provide significant cost savings to healthcare payors, as the cost of over-prescription of individual medications is lessened. 


\section{TABLE 4 Overall Cost of Prescription per 1,000 Patients, AWP Minus $60 \%$, for Individual Opioids}

\begin{tabular}{l|r|r|r|r}
\hline \multirow{2}{*}{\multicolumn{1}{c|}{ Medication }} & \multicolumn{3}{|c}{ Cost of prescription per 1,000 patients minus 60\% AWP } \\
\cline { 2 - 5 } & & & $\begin{array}{r}\text { Difference } \\
\text { between } \\
\text { Phase I } \\
\text { and II, \$ }\end{array}$ & P value \\
\hline Hydrocodone w/APAP 5/325 mg & $12,337.94$ & $6,665.65$ & $5,672.29$ & $<0.001$ \\
\hline Hydrocodone W/APAP 10/325 mg & 256.00 & 279.80 & 23.80 & 0.170 \\
\hline Oxycodone w/APAP 5/325 mg & $3,024.00$ & $2,411.41$ & 612.59 & 0.732 \\
\hline Hydromorphone 2 mg & 222.17 & 149.62 & 72.55 & 0.930 \\
\hline Oxycodone CR 10 mg & $1,850.26$ & 130.30 & $1,719.96$ & $<0.001$ \\
\hline Morphine CR 15 mg & 180.80 & $\$ 27.08$ & 153.72 & 0.009 \\
\hline APAP w/codeine 300/30 mg & 53.62 & 37.42 & 16.20 & 0.867 \\
\hline Oxycodone 5 mg & $2,575.06$ & $1,858.86$ & 716.20 & 0.804 \\
\hline Oxycodone 10 mg & 26.06 & 43.94 & 17.88 & 0.481 \\
\hline Tramadol 50 mg & 341.71 & 420.87 & 79.16 & 0.012 \\
\hline
\end{tabular}

\section{TABLE 5 Overall Cost of Consumption per 1,000 Patients, AWP Minus $60 \%$, for Individual Opioids}

\begin{tabular}{|c|c|c|c|c|}
\hline \multirow[b]{2}{*}{ Medication } & \multicolumn{4}{|c|}{ Cost of consumption per 1,000 patients Minus $60 \%$ AWP } \\
\hline & Phase I, \$ & Phase II, \$ & $\begin{array}{c}\text { Difference } \\
\text { between } \\
\text { Phase I } \\
\text { and II, \$ }\end{array}$ & $P$ value \\
\hline Hydrocodone w/APAP 5/325 mg & $5,304.40$ & $3,135.61$ & $2,168.79$ & $<0.001$ \\
\hline Hydrocodone W/APAP 10/325 mg & 96.00 & 145.06 & 49.06 & 0.233 \\
\hline Oxycodone W/APAP 5/325 mg & $1,750.08$ & $1,269.35$ & 480.73 & 0.841 \\
\hline Hydromorphone $2 \mathrm{mg}$ & 111.09 & 95.77 & $\$ 15.32$ & 0.892 \\
\hline Oxycodone CR 10 mg & $\$ 688.66$ & 63.39 & 625.27 & $<0.001$ \\
\hline Morphine CR 15 mg & 116.23 & 18.09 & 98.14 & 0.003 \\
\hline APAP w/codeine $300 / 30 \mathrm{mg}$ & 15.51 & $\$ 12.05$ & 3.46 & 0.728 \\
\hline Oxycodone $5 \mathrm{mg}$ & $1,287.53$ & 974.08 & 313.45 & 0.701 \\
\hline Oxycodone $10 \mathrm{mg}$ & 17.37 & 24.92 & 7.55 & 0.818 \\
\hline Tramadol $50 \mathrm{mg}$ & 181.26 & 169.51 & 11.75 & 0.037 \\
\hline
\end{tabular}

In addition to the direct cost reduction by reducing both the number of opioid pills prescribed, consumed, and wasted, there are indirect cost-savings that could attributed to this work as well. According to the $\mathrm{CDC}$, anyone who takes a prescription opioid can become addicted. Therefore, in order to minimize that risk, prescribers have been encouraged to limit the number of opioid pills prescribed and limit the duration of opioid treatment, as well as limit the MEUs. The National Institute on Drug Abuse (NIDA) estimates the annual cost of opioid use disorder to be $\$ 6,552$ for methadone treatment programs, $\$ 5,980$ for buprenorphine treatment programs and $\$ 14,112$ for naltrexone-based treatment programs. ${ }^{21}$ To put that into perspective, the Agency for Healthcare Research and Quality reports the annual cost of care for those with diabetes and kidney disease are $\$ 3,560$ and $\$ 5,624$, respectively. ${ }^{21}$ NIDA also references an analysis that estimates the total annual cost of prescription opioid use disorders and overdoses in the United States to be $\$ 78$ billion (2013), with only $3.6 \%$ of that cost being attributed to treatment. ${ }^{21}$ The economic burden of opioid use disorders is significant and impacts many different aspects of our society. Every effort made to standardize opioid prescribing based on evidence, while optimizing the number of opioid pills prescribed, and reducing the number of pills available for misuse, may positively impact the downstream economic burden of opioid use disorders. Further work and analysis is needed to investigate how the direct reduction of opioid pills prescribed impacts the indirect cost of reducing the incidence of opioid use disorders.

For years, the medical community has focused on curtailing opioid prescriptions to address the opioid epidemic. In particular, since this effort to reduce prescriptions is widespread, involving many different healthcare providers, prescribing rates for certain opioid prescriptions have been steadily declining since $2010 .^{22}$ As a result of these widespread efforts to reduce opioid prescriptions, it is likely that physician prescribing behavior and patient consumption behavior was impacted to a certain extent by influences outside of the prescription guidelines highlighted in the study. That being addressed, 


\section{TABLE 6 Overall Cost of Waste per 1,000 Patients, AWP Minus $60 \%$, for Individual Opioids}

\begin{tabular}{l|r|r|r|r}
\hline \multirow{2}{*}{\multicolumn{1}{c|}{ Medication }} & \multicolumn{3}{|c}{ Cost of waste per 1,000 patients minus 60\% AWP } \\
\cline { 2 - 5 } & & & $\begin{array}{r}\text { Difference } \\
\text { between } \\
\text { Phase I } \\
\text { and II, \$ }\end{array}$ & P value \\
\hline Hydrocodone w/APAP 5/325 mg & $7,033.54$ & $3,530.04$ & $3,503.50$ & $<0.001$ \\
\hline Hydrocodone W/APAP 10/325 mg & 160.00 & 134.74 & 25.26 & 0.289 \\
\hline Oxycodone w/APAP 5/325 mg & $1,273.92$ & $1,142.06$ & 131.86 & 0.676 \\
\hline Hydromorphone 2 mg & 111.09 & 53.86 & 57.23 & 0.931 \\
\hline Oxycodone CR 10 mg & $1,161.60$ & 66.91 & $1,094.69$ & $<0.001$ \\
\hline Morphine CR 15 mg & 64.57 & 8.99 & 55.58 & 0.001 \\
\hline APAP w/codeine 300/30 mg & 38.11 & 25.37 & 12.74 & 0.957 \\
\hline Oxycodone 5 mg & $1,287.53$ & 884.78 & 402.75 & 0.791 \\
\hline Oxycodone 10 mg & 8.69 & 19.02 & 10.33 & 0.888 \\
\hline Tramadol 50 mg & 160.46 & 251.36 & 90.90 & 0.014 \\
\hline
\end{tabular}

the purpose of the analysis was to highlight the economic impact of reducing the number of wasted opioids, not to completely attribute the overall reduction to the implementation of prescribing guidelines. Overall, the prescription guidelines were implemented to enhance the decision-making process for surgeons as to how many opioids to prescribe for a specific orthopedic surgery. A positive result of this work is the clear reduction of prescription opioid waste and the cost of opioid prescription waste.

A major strength of this study was that a consistent, reliable recommendation for prescription guidelines based on the science of patient consumption, pain management, and procedure was able to be created. This helped give surgeons guidance, who may have otherwise based their prescribing on experiences from their mentors without consideration for the potential for wasted prescriptions. One thing that was learned throughout the project was that there also needed to be education for advanced practice providers regarding the prescription guidelines. The recommendation for the internal guidelines took longer to complete because these providers were prescribing based on historic physician requests. That being said, this study demonstrates that prescription guidelines may feasibly be implemented into other practices looking to reduce opioid prescription, consumption, and cost.

\section{LIMITATIONS}

The primary limitation of this study is that patients self-reported their opioid consumption. We could not control for any potential errors in their reporting. Furthermore, the mode of consumption data collection varied between Phase I and Phase II. Phases I relied on patient interviews via phone call while Phase II initially relied on patient interviews via phone calls and later automatic, online patient surveys. The automatic online surveys contributed to the larger sample size in Phase II and continue throughout the organization today. Yet, this must be mentioned as a potential cause of self-reporting error. Since the intention of this study was to reduce opioid prescriptions across the whole practice, there was no control group. Finally, as mentioned in the discussion, opioid prescriptions have been decreasing, secondary to addressing the opioid epidemic. ${ }^{21}$ As a result, physician prescribing behavior may have been impacted by the national focus of decreasing over-prescription.

\section{Conclusions}

Overall, the results of this study have several important economic implications for health care patients, providers, and payors. Specifically, as this study demonstrates, there is a significant amount of monetary waste in orthopedic surgery that may be attributed to the inefficient overprescription and under-consumption of prescription opioids. However, this cost of waste associated with differences in prescribed versus consumed opioids may be significantly reduced by introducing formal prescription guidelines. By lessening the cost of waste of opioids following orthopedic surgery, economic cost savings may be enjoyed by patients, providers, and payors.

\section{DISCLOSURES}

This study was funded internally by Revo Health and Twin Cities Orthopedics. Giveans reports consulting fees from Medtrak, Inc., and Superior Medical Experts. The other authors have nothing to disclose.

\section{ACKNOWLEDGMENTS}

The authors would like to thank Dean M. Erickson and Ryan A. Moon for their assistance in data collection. 


\section{REFERENCES}

1. Almanie SA, Holdford DA. Economic impact of waste in Prescribing, Dispensing, and Medication consumption in the United States. Value Heal. 2015;18(3):A81-A82.

2. Law AV, Sakharkar P, Zargarzadeh A, et al. Taking stock of medication wastage: Unused medications in US households. Res Soc Adm Pharm. 2015;11(4):571-78.

3. Substance Abuse and Mental Health Services Administration. 2018 National Survey on Drug Use and Health: Methodological summary and definitions. Accessed October 20, 2020. https:// www.samhsa.gov/data/

4. Scholl L, Seth P, Kariisa M, Wilson N, Baldwin G. Drug and Opioid-Involved Overdose Deaths-United States, 2013-2017. MMWR Morb Mortal Wkly Rep. 2019;67(5152):1419-27.

5. Bree R. Supplemental guidance on prescribing opioids for postoperative pain at time of discharge clinical recommendations. Published July 2018. Accessed October 12, 2020. http://www.agencymeddirectors.wa.gov/Files/ FinalSupBreeAMDGPostopPain 091318wcover.pdf

6. Prescription Drug \& Opioid Abuse Comission. Acute care opioid treatment and prescribing recommendations: summary of selected best practices. Updated June 26, 2018. Accessed August 15, 2020. https://www.michigan. gov/documents/lara/AcuteCareOpioid TreatmentandPrescibing_Recommenda tions_Surgical_-_FINAL_620739_7.pdf

7. Thiels CA, Anderson SS, Ubl DS, et al. Wide variation and overprescription of opioids after elective surgery. Ann Surg. 2017;266(4):564-73.
8. Kaiser Family Foundation. Analysis: cost of treating opioid addiction rose rapidly for large employers as the number of prescriptions has declined. Published April 5, 2018. Accessed October 15, 2020. https:// www.kff.org/health-costs/press-release/ analysis-cost-of-treating-opioid-addiction-rose-rapidly-for-large-employersas-the-number-of-prescriptions-has-declined/

9. Volkow ND, McLellan TA, Cotto JH, Karithanom M, Weiss SRB. Characteristics of opioid prescriptions in 2009. JAMA. 2011;305(13):1299-301.

10. Sabatino MJ, Kunkel ST, Ramkumar DB, Keeney BJ, Jevsevar DS. Excess Opioid Medication and Variation in Prescribing Patterns Following Common Orthopaedic Procedures. J Bone Joint Surg Am. 2018;100(3):180-188

11. Kim N, Matzon JL, Abboudi J, et al. A Prospective Evaluation of Opioid Utilization After Upper-Extremity Surgical Procedures: Identifying Consumption Patterns and Determining Prescribing Guidelines. J Bone Joint Surg Am. 2016;98(20):e89.

12. Korol S. $38+$ of the largest orthopedic groups in the US. Becker's Spine Review. May 22, 2019. Accessed August 15, 2020. https://www.beckersspine.com/orthopedic-spine-practices-improving-profits / item/39873-34-of-the-largest-orthopedic-groups-in-the-us.html

13. Medi-Span. In: Post TW, ed. UpToDate Hudson, Ohio; UpToDate, Inc; 2020; Accessed July 6, 2020.

14. Pal S. Trends in Drug Shortages. US Pharm. 2013;38(10):7.

15. Blue Cross Blue Shield Association. Planned knee and hip replacement surgeries are on the rise in the US Published January 23, 2019. Accessed August 27, 2020. https://www.bcbs.com/ sites/default/files/file-attachments/ health-of-america-report/HoAOrthopedic\%2BCosts\%20Report.pdf
16. Sabesan VJ, Petersen-Fitts GR, Ramthun KW, Brand JP, Stine SA, Whaley JD. Strategies to contain cost associated with orthopaedic care. JBJS Rev. 2018;6(2):e3.

17. Sathiyakumar V, Jahangir AA, Mir HR, et al. Patterns of costs and spending among orthopedic surgeons across the United States: a national survey. Am J Orthop (Belle Mead NJ). 2014;43(1):E7-13.

18. Wyles CC, Hevesi M, Trousdale ER, et al. The 2018 Chitranjan S. Ranawat, MD Award: Developing and implementing a novel institutional guideline strategy reduced postoperative opioid prescribing after TKA and THA. Clin Orthop Relat Res. 2019;477(1):104-13.

19. Wyles CC, Hevesi M, Ubl DS, et al. Implementation of procedure-specific opioid guidelines: A readily employable strategy to improve consistency and decrease excessive prescribing following orthopaedic surgery. JB JS Open Access. 2020;5(1):e0050.

20. Wunsch H, Wijeysundera DN, Passarella MA, Neuman MD. Opioids prescribed after low-risk surgical procedures in the United States, 2004-2012. JAMA. 2016;315(15):1654-57.

21. National Institute on Drug Abuse. "How much does opioid treatment cost?" Published June 2018. Accessed October 21, 2020. https://www.drugabuse. gov/publications/research-reports/ medications-to-treat-opioid-addiction/ how-much-does-opioid-treatment-cost

22. Schieber LZ, Guy GP Jr, Seth P, et al. Trends and patterns of geographic variation in opioid prescribing practices by state, United States, 2006-2017. JAMA Netw Open. 2019;2(3):e190665. 